\title{
EXPERIÊNCIA E AMOROSIDADE: ABRINDO CAMINHOS PARA A PESQUISA
}

\author{
EXPERIENCE AND LOVINGNESS: OPENING PATHWAYS TO RESEARCH \\ EXPERIENCIA Y AMOROSIDAD: ABRIENDO CAMINOS PARA LA \\ INVESTIGACIÓN
}

\author{
PILLOTO, Silvia Sell Duarte \\ pillotto0@gmail.com \\ UNIVILLE - Universidade da Região de Joinville \\ SILVA, Carla Clauber da \\ carlaclauber@hotmail.com \\ UNICAMP - Universidade Estadual de Campinas
}

\begin{abstract}
RESUMO O artigo busca refletir sobre a necessidade de se legitimar outros modos de pesquisar na academia, uma vez que ainda hoje tal cultura está enraizada em pressupostos estabelecidos pelo método científico. O objetivo é reiterar que a pesquisa é uma escolha conectada ao pesquisador e aos seus interlocutores, pois durante o processo investigativo produzem conhecimentos e metodologias, que se desdobram em múltiplos olhares. De abordagem qualitativa, o artigo apoia-se na leitura bibliográfica e em pesquisas (entre)laçadas, nas quais o compartilhamento de ideias, a experiência e a amorosidade se fazem presentes. Os resultados apontam para a importância de pesquisados e pesquisadores tornarem-se sujeitos da pesquisa, abertos a outros movimentos de pensares e sentires, invertendo a lógica do método científico por um modo provisório e inacabado de pesquisar.
\end{abstract}

Palavras-chave: Amorosidade. Cartografia. Experiência. Pesquisa.

\begin{abstract}
The article seeks to reflect on the need to legitimize other ways of researching in academia, since it is still rooted in assumptions established by the scientific method. The objective is to reiterate that research is a choice connected to the researcher and his/her interlocutors, since during the investigative process they produce knowledge and methodologies that unfold in multiple panoramas. From a qualitative approach, the article is based on bibliographical reading and on research (between) loops in which the sharing of ideas, experience and love are present. The results point to the importance of researchers and researchers becoming subjects of research, open to other movements of thoughts and feelings, reversing the logic of the scientific method by a temporary and unfinished manner of researching.
\end{abstract}

Keywords: Cartography. Experience. Lovingness. Research.

RESUMEN El artículo busca reflexionar sobre la necesidad de legitimar otras formas de investigar en la academia, ya que aún hoy está enraizada en supuestos establecidos por el método científico. El objetivo es reiterar que la investigación es una elección conectada al investigador y sus interlocutores, pues durante el proceso investigativo producen conocimientos y metodologías, que se desdoblan en múltiples miradas. De abordaje cualitativo, el artículo se apoya en la lectura bibliográfica y en investigaciones entrelazadas dónde el compartir ideas, la experiencia y la 
amorosidad se hacen presentes. Los resultados apuntan a la importancia de que los investigados e investigadores se vuelvan sujetos de la investigación, abiertos a otros movimientos de pensamientos y sentimientos, invirtiendo la lógica del método científico por una forma provisional e inacabado de investigar.

Palabras clave: Amorosidad. Cartografía. Experiencia. Investigación.

\section{INICIANDO NOSSA CONVERSA}

$\mathrm{O}$ artigo aqui apresentado tem como objetivo refletir sobre a necessidade de se legitimar outros modos de investigar na academia, uma vez que se observa que a cultura de pesquisa está enraizada em pressupostos estabelecidos pelo método científico. Esse determinismo tem como consequência o enquadramento do pensamento e do que é considerado conhecimento. A pesquisa é compreendida, por nós, como o lugar da experiência e da amorosidade.

Nessa perspectiva, inverte-se o modelo do método científico, que tem em suas bases a busca pela permanência da verdade, substituindo-o por um modo provisório, inacabado, em vias de se fazer a cada vez o conhecimento produzido, ou seja, o que se pretende é dar visibilidade para o percurso da pesquisa e seus processos.

Com base nessas breves considerações, um dos objetivos do presente artigo é reiterar que a pesquisa é uma escolha conectada ao pesquisador e aos seus interlocutores, que durante seu processo investigativo produzem conhecimentos e metodologias que se desdobram em múltiplos olhares e afetamentos da/na própria pesquisa.

De abordagem qualitativa, o referido artigo apoia-se na leitura bibliográfica e nas experiências realizadas em um núcleo de pesquisa de uma universidade, que desde 2014 desenvolve investigações que se (entre)laçam entre os pesquisadores.

A abordagem das pesquisas do núcleo tem, em sua maioria, cunho cartográfico, afetando o modo de se fazer pesquisa e de produzir conhecimento, pois a cartografia é um desenho de mapas processuais. Essa abordagem compreende que o objeto de estudo não é algo fixo, mensurável e/ou categorizável. Outra característica da abordagem é a coletividade, porque é relacional, política e 


\section{Atos de Pesquisa em Educação - ISSN 1809-0354 \\ Blumenau, v.14, n.1, p.7-28 jan./abr. 2019 \\ DOI: http://dx.doi.org/10.7867/1809-0354.2019v14n1p7-28}

constitui um modo de expressão nas relações entre os sujeitos e estes com o mundo.

Salientamos que as pesquisas produzidas pelo núcleo se sustentam no trabalho compartilhado, na experiência, na amorosidade e, especialmente, nos afetamentos que emergem durante o processo cartográfico. Compreendemos, então, com base nos estudos bibliográficos e nas produções científicas produzidas pelo núcleo, que a pesquisa em educação na sua dimensão qualitativa pode também abrigar outros sentidos, significados e experiências, tanto do pesquisador quanto dos seus interlocutores.

Para que possamos adentrar mais profundamente nas questões postas nesta introdução, o artigo está estruturado nos seguintes itens: Pesquisa e cartografia: percursos (entre)laçados, item que traz experiências em pesquisas entre pesquisadores do núcleo, que anunciam novas perspectivas de se fazer pesquisa, nas quais o compartilhamento de ideias, a experiência e a amorosidade se fazem presentes. No item Potencializando a experiência do pesquisador, destacamos a pesquisa como possibilidade de experiência do próprio pesquisador, envolvendo a dimensão do ato de pesquisar. Experiência que não se reduz ao processo apenas de investigar, mas sobretudo a uma prática da própria existência. Latência amorosa nos processos de pesquisar, nosso último item, potencializa a imersão sensível do pesquisador e seus interlocutores - sujeitos da pesquisa -, que assumem o papel de coautoria no ato de pesquisar.

\section{PESQUISA E CARTOGRAFIA - PERCURSOS (ENTRE)LAÇADOS}

A pesquisa é sempre uma escolha conectada aos pesquisadores e aos seus interlocutores. Há algum tempo esse tem sido o lema do núcleo de pesquisa ao qual pertencemos. E mais do que isso, pensar em possibilidades de pesquisas (entre)laçadas que permeiam caminhos comuns e singulares entre pesquisadores e coautores da pesquisa.

As pesquisas (entre)laçadas de nosso núcleo são um convite ao desconhecido, ao quase improvável, ao improviso. Ao colocar uma linha tênue entre 
o real e o imaginário, a construção na desconstrução e o inevitável afetamento, a pesquisa toma novos rumos, por vezes totalmente desconhecidos.

Portanto, nosso ponto de apoio tem sido a experiência compreendida e sentida como um saber que emerge do fazer/pensar/fazer. E assim, múltiplas são as entradas numa pesquisa cartográfica, configurando-se em um mapa móvel, que se desloca entre saberes e sentires. Ou seja, são as pistas que guiam os processos e percursos da pesquisa (PASSOS; KASTRUP; ESCÓSSIA, 2015).

Em nossos percursos, as artes, a educação e o sensível intercruzam-se no ensinar aprendendo e no aprender ensinando. Nesse processo, não há uma hierarquia entre pesquisador e pesquisado, pois somos todos autores de conhecimentos que se multiplicam em experiências e afetamentos. Viver aprendendo é o que tem nos guiado em nossas pesquisas.

E foi exatamente assim que aconteceu nas pesquisas de quatro pesquisadores do nosso núcleo. Pelo viés da educação, das sensibilidades e das artes, os pesquisadores, com suas distintas áreas de atuação - música, dança e artes visuais - e em espaços formais e não formais da educação, constituíram suas pesquisas com ritmos ora singulares, ora compostos de partilhas e experiências. 
Figura 1: Mapa cartográfico das pesquisas (entre)laçadas do NUPAE

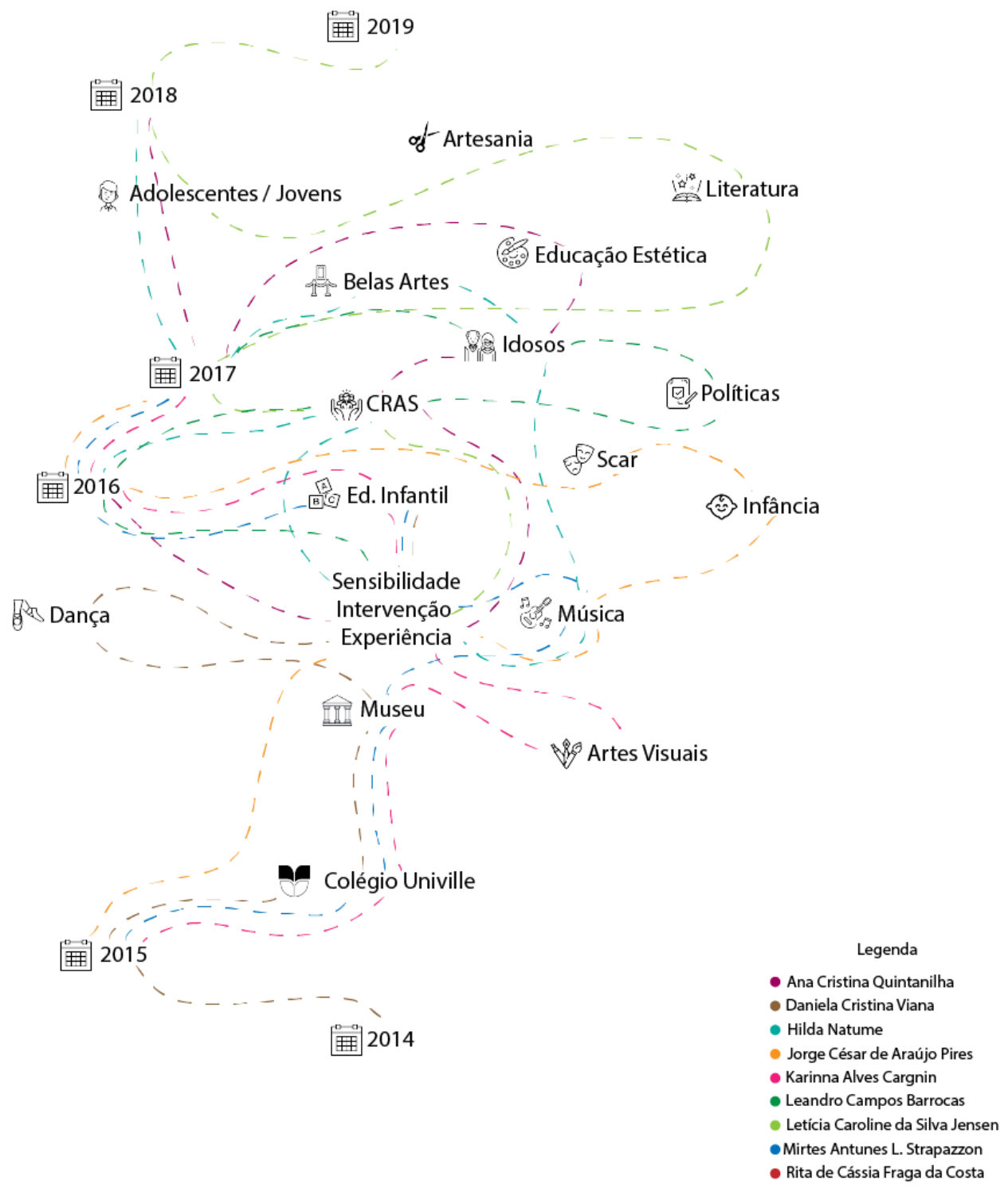

Fonte: das autoras, 2018.

Uma das pesquisas, cujo tema é Mediação cultural por meio da dança/educação como possibilidade de aprendizagem na infância, teve como ponto de partida ajuizar a dança/educação na infância como ação de interação e vivência corpóreo/sensível. As pistas reiteraram a ideia de que a dança/educação como mediação cultural potencializa aprendizagens, estabelecendo um canal de comunicação afetivo, pois a criança se manifesta interagindo com espaços e outros 


\section{Atos de Pesquisa em Educação - ISSN 1809-0354 \\ Blumenau, v.14, n.1, p.7-28 jan./abr. 2019 \\ DOI: http://dx.doi.org/10.7867/1809-0354.2019v14n1p7-28}

sujeitos, aprendendo a conviver com o outro e iniciando um processo de autoconhecimento.

Outra pesquisa, Vivências perceptivas com a infância nos espaços da escola e do museu - uma experiência teve como ponto de partida concretizar ações de mediação cultural em espaços formais e não formais da educação (escola e museu) com crianças, identificando como se dão as vivências perceptivas e quais suas contribuições nos aspectos sensíveis. As pistas revelaram que experiências com as linguagens/expressões das artes e seus atravessamentos nos espaços da escola e do museu propulsionaram processos de criação e construção de relações entre os seres humanos, os objetos e os territórios.

Continuando o (entre)laçamento das pesquisas, Uma cartografia com a infância: experiências e múltiplas sonoridades teve como intuito produzir ações de mediação/interlocução com experiências sonoras na infância, tendo a cartografia e suas pistas como base teórico-metodológica, buscando a transversalidade como potência de ação sensível com as crianças (as mesmas das duas pesquisas anteriores). Pistas mostraram-nos que as experiências sonoras na infância podem contribuir para a ampliação da escuta, da observação, da interação entre os sujeitos, e especialmente para a sensibilização sonora e cultural.

Por fim, a pesquisa Sentidos e experiências na docência: processos de aprendizagem do instrumento musical na infância teve como alicerce refletir sobre os percursos utilizados pelos professores nos processos de mediação no ensino e na aprendizagem de diferentes instrumentos musicais com crianças de 9 a 12 anos. A pesquisa apontou que os professores consideram importantes as questões relacionadas ao sensível, mas que na prática tais conceitos se diluem e ainda prevalecem os aspectos técnicos. No entanto, o movimento de pesquisa provocou reflexões sobre o ensino e a aprendizagem dos instrumentos, marcando significativamente uma oscilação dos professores para pensar as suas práticas e conceitos sobre a temática da pesquisa em ação.

O que foi comum para as quatro pesquisas? A infância, os caminhos pelos campos de pesquisa: escola, museu, centro de artes, as experiências sensíveis, a educação e a cartografia. $E$ o que diferiu nessas pesquisas? As 


\section{Atos de Pesquisa em Educação - ISSN 1809-0354 \\ Blumenau, v.14, n.1, p.7-28 jan./abr. 2019 \\ DOI: http://dx.doi.org/10.7867/1809-0354.2019v14n1p7-28}

linguagens/expressões: enquanto dois pesquisadores tratavam da música, outro se centrava nas questões relacionadas ao corpo/movimento, e outro, no desenho e na modelagem.

As crianças, coautoras das quatro pesquisas, faziam esse mesmo movimento de atravessamento, pois, enquanto desenhavam, cantavam e se movimentavam; enquanto sonorizavam, narravam histórias; enquanto dançavam, desenhavam e movimentavam-se. Nesse processo de atravessamento, puderam ampliar o potencial da escuta, do corpo, da visão e de tantos outros sentidos. Os sons, as cores marcadas em linhas diversas sobre os papéis e o ritmo de corpos curiosos (entre)laçavam-se em lugares reais e imaginários.

Nessa trama de sons, imagens e corpos, os professores desempenharam papel importante como autores do conhecimento produzido nas pesquisas. Uma palavra, um gesto, um suspiro ou um simples movimento corporal sinalizava ideias, inquietações e, por vezes, um olhar diferenciado para suas próprias práticas.

E quais caminhos/pesquisas (entre)laçadas seguem? Um caminho sem saber muito bem para onde ele leva. Pesquisas (entre)laçadas são constituídas de experiências e pistas, que acompanham os pesquisadores em suas produções de conhecimentos e vão acontecendo no próprio percurso de investigação.

Esse trajeto implica mobilidade entre os sujeitos e as situações, expansão de ideias e de conceitos e, principalmente, contaminação entre sujeitos, territórios e processos de pesquisa. O conhecimento vai se inventando, quando, "como cartógrafos, nos aproximamos do campo como estrangeiros visitantes de um território que não habitamos. O território vai sendo explorado por olhares, escutas, pela sensibilidade aos odores, gostos e ritmos" (PASSOS; KASTRUP; ESCÓSSIA, 2015, p. 61).

O (entre)laçamento de pesquisas busca superar a verticalidade e a horizontalidade do pensamento, procurando o diálogo entre as diferentes pessoas, situações e territórios, de modo a construir diferentes sentidos. É sustentado pela ideia do movimento em territórios diversos, que de alguma forma se conectam. Os pesquisadores se encontram em condição instável, entre o comum e o diferente; entre o que conecta as diferenças entre os sujeitos e as situações imbricadas na 
pesquisa e o que nessas relações tenciona, entre o que norteia o conhecimento pela via da ciência e o que desse conhecimento mergulha na experiência (OPIPARI; TIMBERT, 2014).

As pesquisas (entre)laçadas dos quatro pesquisadores aqui em questão oportunizaram às crianças e aos professores envolvidos o papel de interlocutores, construindo diálogos e sendo partícipes de todo o processo de mediação com as múltiplas linguagens/expressões das artes. Foi no diálogo que se privilegiaram a escuta, o silêncio e o sensível na relação consigo e com o outro, levando-nos às experiências.

$\mathrm{Na}$ abordagem cartográfica, a experiência é o alicerce para as percepções do que é investigado. Quando utilizamos o termo abordagem, temos a intenção de nos distanciarmos "[...] de pontos de vista que tomam a metodologia como conjunto de normas absolutas, prescrições técnicas e procedimentos imperativos, não falamos de regras fixas" (PASSOS; KASTRUP; TEDESCO, 2014, p. 9).

E nos percursos de pesquisas (entre)laçadas, o transversal também perpassa pelo rizoma, que na visão de Deleuze e Guattari (1995, p. 33)

[...] não começa nem conclui, ele se encontra sempre no meio, entre as coisas, inter-ser, intermezzo. A árvore é filiação, mas o rizoma é aliança, unicamente aliança. A árvore impõe o verbo ser, mas o rizoma tem como tecido a conjunção "e...e...e". Há nessa conjunção força suficiente para sacudir e desenraizar o ver ser.

Na sequência das pesquisas (entre)laçadas realizadas em nosso núcleo de pesquisa, vale apresentar outros três pesquisadores que trilharam nessa perspectiva: um tratando das questões da estética, com o tema Memórias e sentidos na terceira idade: experiências pela via da estética, que analisou as práticas educativas pela via da estética na terceira idade. Como referência à ação mediadora e à sensibilidade, mobilizou memórias e experiências na construção de sentidos e relações com o cotidiano. Outra pesquisa desenvolveu o tema Musicalização: memórias, experiências e sensibilidades na terceira idade, tendo como ponto de partida pensar a ação mediadora em práticas educativas. A musicalização, nessa pesquisa, mobilizou experiências em que memórias e sentidos puderam ser 


\section{Atos de Pesquisa em Educação - ISSN 1809-0354 \\ Blumenau, v.14, n.1, p.7-28 jan./abr. 2019 \\ DOI: http://dx.doi.org/10.7867/1809-0354.2019v14n1p7-28}

ativados, constituindo relações com a vida cotidiana na terceira idade. A última pesquisa desse grupo de pesquisadores - Sentidos e significados atribuídos pelos idosos às práticas educativas - teve como ponto de intersecção a reflexão sobre os sentidos e significados atribuídos por idosos às práticas educativas vivenciadas num Centro de Referência de Assistência Social (CRAS) articuladas às políticas públicas para a terceira idade.

O ponto de intercruzamento entre essas três investigações foi um grupo da terceira idade e o território, um CRAS. Cada um dos pesquisadores deu luz a um determinado argumento (estética, musicalização e políticas públicas).

As pesquisas (entre)laçadas revelaram algumas pistas muito interessantes, a exemplo: Memórias e sentidos na terceira idade: experiências pela via da estética sinalizou que as memórias podem ser despertadas por meio de experiências estéticas, trazendo à tona as histórias pessoais, e que o ato de revisitá-las pode ser (re)significado ao seu cotidiano.

Já a pesquisa Musicalização: memórias, experiências e sensibilidades na terceira idade apontou a musicalização como propulsora das memórias dos idosos por intermédio de vivências das músicas e letras de outras épocas de sua vida, mobilizando-os a valorizar o ontem como essencial no seu dia a dia.

E por fim, Sentidos e significados atribuídos pelos idosos às práticas educativas revelou que as práticas educativas e as políticas públicas podem proporcionar uma formação mais humanista, capaz de provocar o sentido de cidadania plena, particularmente nos sujeitos da terceira idade. Para os idosos o CRAS é um lugar de acolhimento e de convivência, cujas práticas educativas proporcionam um novo sentido para a vida dos que o frequentam.

As pistas desveladas nas pesquisas (entre)laçadas serviram para nos guiar nos processos de investigação, mas sem impor caminhos definitivos, pois para o cartógrafo são "como referências que concorrem para a manutenção de uma atitude de abertura ao que vai se produzindo e de calibragem do caminhar no próprio percurso da pesquisa" (PASSOS; KASTRUP; ESCÓSSIA, 2015, p. 13).

A abordagem cartográfica é assumida nessas pesquisas (entre)laçadas como performance de pesquisa em que os processos e os movimentos da investigação 


\section{Atos de Pesquisa em Educação - ISSN 1809-0354 \\ Blumenau, v.14, n.1, p.7-28 jan./abr. 2019 \\ DOI: http://dx.doi.org/10.7867/1809-0354.2019v14n1p7-28}

são acompanhados, e não somente resultados são apontados. Os três pesquisadores estiveram sempre juntos no campo de pesquisa em seus percursos, que envolviam grupos de discussão, experiência estética em artes visuais e musicalização e expedições em espaços de arte.

No plano da experiência, os objetivos e a problemática procuram aproximar conhecimento e criação, que se configuram como política cognitiva, enquanto tratam da complexidade ética-estética-política da ação do pesquisador. Essas práticas de produção de conhecimento consideram a coletividade, o deslocamento de pontos de vista, a ocupação de territórios, os movimentos e a apuração da atenção, entre outros percursos (PASSOS; KASTRUP; ESCÓSSIA, 2015).

Atualmente, mais dois pesquisadores (entre)laçam suas pesquisas em duas áreas distintas: literatura e artesania. Ambas as investigações no mesmo território e com protagonistas de idades diferentes - adolescentes e idosos que frequentam um CRAS.

A pesquisa Experiências sensíveis atravessadas pela literatura em espaços não formais de educação ${ }^{1}$ problematiza sobre como experiências sensíveis por meio da literatura em forma de oficinas estéticas mobilizam novas maneiras de pensar/sentir de um grupo de adolescentes.

$\mathrm{Na}$ produção de dados, algumas pistas têm sido relevantes, como: a abordagem sensível com textos literários permitiu que os adolescentes socializassem suas próprias histórias, ao mesmo tempo em que as (re)significavam. Com a leitura e a escrita, eles fortaleceram vínculos afetivos, compartilhando experiências e restabelecendo a confiança em grupo. Além disso, as autobiografias mostraram-se significativas na vida dos adolescentes, principalmente para aqueles que vivenciam um contexto de vulnerabilidade social.

A pesquisa Artesania: formação cultural, construções identitárias e experiências sensíveis na terceira idade ${ }^{2}$ tem buscado compreender como experiências em artesania com a terceira idade são constituídas de memórias e construções identitárias. Nesse âmbito, o desafio tem sido oportunizar práticas

\footnotetext{
1 Esta pesquisa está em andamento no NUPAE e é de autoria de Letícia Caroline da Silva Jensen.

2 Esta pesquisa está em andamento no NUPAE e é de autoria de Rita de Cássia Fraga da Costa.
} 
educativas mobilizando as potencialidades de cada um. Algumas pistas têm sido fundamentais para nossas reflexões, especificamente no reconhecimento de saberes da terceira idade e na formação e valorização cultural desses sujeitos.

Importante salientar que os territórios de tais pesquisas não são estáticos, assim como o mapa que tem nos guiado na cartografia não é definitivo. Trabalhamos com a territorialização e a reterritorialização no processo constante de pertencimento e não pertencimento a certas regiões criadas pela pesquisa. É por isso que já não se sustenta a separação entre pesquisador e pesquisados, entre sujeitos e campo de pesquisa, entre emoção e razão, assim como destacam Deleuze e Guattari (2010, p. 132):

A desterritorialização e a reterritorialização se cruzam no duplo devir. Não se pode mais distinguir o autóctone e o estrangeiro, porque o estrangeiro se torna autóctone no outro que não o é, ao mesmo tempo que o autóctone se torna estrangeiro a si mesmo, a sua própria classe, a sua própria nação, a sua própria língua: nós falamos a mesma língua, e todavia eu não entendo você...

Daí que pesquisa em cartografia é intervenção/invenção e criação. O pesquisador está em constante movimento, sabendo que o programado pode não funcionar, que será preciso recalcular a rota, mas que, nem por isso, sua pesquisa será fracassada. Tem sido assim com essas duas pesquisas, ou seja, "não somos mais nós mesmos. Cada um reconhecerá os seus. Fomos ajudados, aspirados, multiplicados" (DELEUZE; GUATTARI, 1995, p. 10).

Para que possamos trilhar nos caminhos da cartografia, é necessário um mergulho profundo no plano da existência. Nesse lugar de experiências, o conhecer e o fazer são inseparáveis, pois ambos estão na dimensão da sensibilidade.

\section{POTENCIALIZANDO A EXPERIÊNCIA DO PESQUISADOR}

Neste item, pretende-se refletir sobre a pesquisa como possibilidade de experiência do próprio pesquisador, porque a concebemos enquanto prática da própria existência do sujeito. Portanto, nossa ideia não se reduz a investigar, estudar de forma sistemática um objeto de conhecimento, ainda que essas ações sejam 


\section{Atos de Pesquisa em Educação - ISSN 1809-0354 \\ Blumenau, v.14, n.1, p.7-28 jan./abr. 2019 \\ DOI: http://dx.doi.org/10.7867/1809-0354.2019v14n1p7-28}

essenciais no processo de pesquisa. No entanto, não são compreendidas por nós como determinantes.

Há muitos autores que descrevem o valor da experiência para o campo educacional, entre eles destacamos Larrosa (2014), o qual argumenta que é possível ultrapassar a dicotomia entre a ciência e experiência e, desse modo, pensar o processo formativo para além do conhecimento científico.

Agamben (2005), na mesma direção, argumenta que, apesar das alterações que a experiência sofreu na contemporaneidade, ela acontece durante o processo, em trânsito. Ou dito de outro modo, na passagem entre a experiência e a linguagem. Para o autor, a necessidade de comprovar a experiência a transformou em experimentos, reduzindo-se a um método. Tal processo teve como consequência a substituição do sujeito da experiência pelo ego cogito cartesiano - a consciência. Desse modo, a formação legitimada tornou-se somente aquela que acontece pelo conhecimento científico por meio dos experimentos.

Isso significa que o espaço do cotidiano, que antes era um lugar privilegiado de encontro entre as gerações, de trocas de saberes e de atualização do passado, enfraqueceu-se e perdeu sua força porque a experiência que se experimenta hoje acontece fora do sujeito. Assim, Agamben (2005) lembra-nos de que hoje uma visita a um museu, a um monumento histórico, a ida a um espetáculo ou outro evento qualquer, pode tornar-se algo meramente instrutivo porque já não é mais o sujeito que o experimenta, mas sim sua máquina fotográfica. Talvez seja por isso que, em um processo investigativo, a pesquisa legitimada é aquela que acontece fora do pesquisador, por meio de fatos e dados que podem ser quantificados, mensurados e decodificados. O que o pesquisador sente, percebe, vive durante a pesquisa muitas vezes não é valorizado nem tampouco legitimado como conhecimento porque não se pode mensurar uma percepção, quantificar uma sensibilidade, explicar com categorias subjetividades que se atravessam durante o ato de pesquisar.

Todavia a impossibilidade de viver a experiência não a retira totalmente da vida dos sujeitos nem da pesquisa. Apoiamo-nos em Agamben (2005), quando afirma que a experiência na contemporaneidade acontece de outro modo. O autor, ao compreender o ego cogito cartesiano como uma realidade linguística, afirma que 


\title{
Atos de Pesquisa em Educação - ISSN 1809-0354 \\ Blumenau, v.14, n.1, p.7-28 jan./abr. 2019 \\ DOI: http://dx.doi.org/10.7867/1809-0354.2019v14n1p7-28
}

o sujeito transcendental é substituído pelo linguístico, constituindo-se assim na e pela linguagem. Nesse sentido, para Agamben (2005), é pela infância que o homem se apropria da linguagem, porém ela não se reduz a uma idade cronológica:

\begin{abstract}
A idéia de uma infância como uma pré-subjetiva revela-se então um mito, como aquela de um sujeito pré-lingüístico, e infância e linguagem parecem assim remeter uma à outra em um círculo no qual a infância é a origem da linguagem e a linguagem a origem da infância. Mas talvez seja justamente neste círculo que devemos procurar o lugar da experiência enquanto infância do homem. Pois a experiência, a infância que aqui está em questão, não pode ser simplesmente algo que precede cronologicamente a linguagem e que, a uma certa altura, cessa de existir para versar-se na palavra, não é um paraíso que, em um determinado momento, abandonamos para sempre a fim de falar, mas coexiste originalmente com a linguagem, constitui-se aliás ela mesma na expropriação que a linguagem dela efetua, produzindo a cada vez o homem como sujeito (AGAMBEN, 2005, p. 59).
\end{abstract}

Nessa perspectiva, o pesquisador não é compreendido por nós como um expectador da pesquisa, um coletor de dados e informações, e sim como sujeito que se constitui na/com e pela pesquisa. Os acontecimentos que atravessam os processos investigativos podem alterar o percurso da pesquisa, o modo de se fazer pesquisa e o próprio pesquisador. Um processo que dá a ver o nascimento de outros pensamentos durante o que se pesquisa e a (re)invenção do pesquisador, especialmente quando experimenta situações múltiplas que não estavam previstas em seu percurso metodológico.

Os acontecimentos tomam os sujeitos e os engendram em um novo trajeto para aprender. A pesquisa não é algo que já está dado, que se descobre, mas se (re)inventa no entrelaçamento entre pesquisador, experiência e conhecimento. São acontecimentos que atravessam o processo de pesquisar e dizem respeito à curiosidade pelo mundo, ao se engajar consigo próprio e com o outro sobre o que se pensa do mundo. Quando compreendemos a pesquisa como acontecimento, percorre-se um caminho que se faz pelos afetamentos:

Todo acontecimento é uma névoa. Se os infinitivos "morrer", "amar", "mover", "sorrir" etc. são acontecimentos, é porque há neles uma parte que sua realização não basta para realizar, um devir em si mesmo que está sempre, a um só tempo, nos esperando e nos precedendo como uma terceira pessoa do infinitivo, uma quarta pessoa do singular. Sim, o morrer engendra-se em nossos corpos, produz-se em nossos corpos, mas chega de fora, singularmente incorporal, e fundindo-se sobre nós como a batalha que 
sobrevoa os combatentes e como o pássaro que sobrevoa a batalha (DELEUZE; PARNET, 2004, p. 78).

Os acontecimentos são singularidades e, para Deleuze (2006), presidem à origem dos sujeitos e das pessoas porque não comportam em si mesmo nem o ego nem o eu, mas os produzem atualizando-se. Assim, a experiência na pesquisa abre brechas para modificar a si próprio porque é um encontro em que a verdade do que se vive se manifesta na própria subjetividade, constituindo-se um processo formativo por excelência para o pesquisador. Nesse viés, a subjetividade

[...] nada mais é que a capacidade do locutor de pôr-se como um ego, que não pode ser de modo algum definida por meio de um sentimento mudo, que cada qual experimentaria da existência de si mesmo, nem mediante a alusão a qualquer experiência psíquica inefável do ego, mas apenas através da transcendência do eu lingüístico relativamente a toda possível experiência (AGAMBEN, 2005, p. 56).

Nessa perspectiva, a pesquisa é lugar e condição da experiência para o pesquisador, em que o pesquisar é um devir, "sempre inacabado, sempre a fazer-se, que extravasa toda a matéria vivível ou vivida" (DELEUZE, 2006, p. 11). O pensamento desdobra-se, experimentam-se detalhes ínfimos e o pesquisador é ele próprio movimento e também pesquisa a si próprio enquanto reflete, analisa, investiga, registra, problematiza seu objeto de conhecimento.

Trata-se de uma pesquisa em que o método não está separado do objeto e não acontece fora do pesquisador, mas em um processo de interação recíproca, que potencializa a experiência intelectual, uma vez que o pensamento não avança em um sentido único, nem mesmo para um lugar fixo e determinado a priori. $\mathrm{Na}$ pesquisa, cada pensamento é um acontecimento porque "[...] há neles uma parte que sua realização não basta para realizar, um devir em si mesmo que está sempre, a um só tempo, nos esperando e nos precedendo como uma terceira pessoa do infinitivo, uma quarta pessoa do singular" (DELEUZE; PARNET, 2004, p. 78).

No caminho do pesquisador, não há mapas fixos, uma vez que a orientação se dá pelos efeitos provocados pelos acontecimentos, em que não há imposição do ser, pois não há começo nem fim, há invenções. A pesquisa se faz território, 


\title{
Atos de Pesquisa em Educação - ISSN 1809-0354 \\ Blumenau, v.14, n.1, p.7-28 jan./abr. 2019 \\ DOI: http://dx.doi.org/10.7867/1809-0354.2019v14n1p7-28
}

desdobrando-se em outros e escolhendo seu próprio percurso. É uma experiência que, para Agamben (2012, p. 117-118), acontece a partir da poiesis:

\begin{abstract}
Os gregos, a quem devemos quase todas as categorias através das quais julgamos a nós mesmos e a realidade que nos circunda, distinguiam, de fato, claramente entre poíesis (poieîn, produzir, no sentido de agir) e práxis (práttein, fazer, no sentido de agir). Enquanto no centro da práxis estava [...] a ideia da vontade que se exprime imediatamente na ação, a experiência que estava no centro da poíesis era a produção na presença, isto é, o fato de que, nela, algo viesse do não-ser ao ser, da ocultação à plena luz da obra. O caráter essencial da poíesis não estava, portanto, no seu aspecto de processo prático, voluntário, mas no seu ser um modo da verdade, entendida como desvelamento.
\end{abstract}

A experiência, portanto, envolve a dimensão da criação e de outros modos de ser que o próprio ofício de pesquisar possibilita. Isso porque os problemas nascem quando se exerce o "poder de decisão, de constituição dos próprios problemas: esse poder, 'semidivino', implica tanto o esvaecimento de falsos problemas quanto o surgimento criador de verdadeiros" (DELEUZE, 1999, p. 9).

Nessa perspectiva, podemos afirmar que a pesquisa permite ao pesquisador viver a experiência, potencializando a autoria e a vontade de criar e de se inventar porque a compreendemos como processo de produção de subjetividade:

\begin{abstract}
A aprendizagem não se dá no plano das formas, não se trata de uma relação entre um sujeito e um mundo composto de objetos. Ao contrário, se faz num encontro de diferenças, num plano de diferenciação mútua, onde tem lugar a invenção de si e do mundo. Sujeito e objeto são efeitos, e não pontos de partida ou pólos pré-existentes. Pois o signo se expressa numa matéria, mas não é objetivo; afeta o sujeito, mas não é subjetivo. Sem ser objeto de recognição, força o movimento da subjetividade. Quando somos tocados pelo signo, pela diferença, temos uma experiência de problematização, de invenção do problema. Só a partir daí ocorre a busca de solução e sentido. Ao acaso dos encontros segue-se a necessidade imposta pelo que nos força a pensar. Aprendemos por coação, forçados pelos signos, ao acaso dos encontros (KASTRUP, 2000, p. 7).
\end{abstract}

Para nós, conceber a pesquisa a partir da experiência, compreendendo-a como um espaço de multiplicidades, significa assumir que o pesquisador não está isento ao que investiga e o que pesquisa não visa apenas à produção de conhecimento, e sim uma modificação de si próprio como pesquisador. Uma experiência que acontece na liberdade, confrontando o pesquisador consigo mesmo, voltada ao modo de conduzir a própria vida. 


\section{LATÊNCIA AMOROSA NOS PROCESSOS DE PESQUISAR}

Está a amorosidade presente nas pesquisas acadêmicas? Ou estamos mais preocupados em resultados e verdades absolutas, como se o que pesquisamos pudesse ser a salvação para todos os problemas? E a paixão de pesquisar e de ser afetado pelo outro está conectada com o que acontece no processo investigativo?

Ao incluir a amorosidade nas ações/relações/interações do pesquisador, os afetos se autoproduzem num campo subjetivo, mais vasto do que da nossa compreensão corpórea, mental e racional. É o amor que transcende qualquer palavra e qualquer ensinamento.

Falar de latência amorosa na pesquisa mostra-se um grande desafio, porém desafio ainda maior é colocá-la em atitudes e em nossas ações como pesquisadores, sobretudo numa sociedade que supervaloriza os resultados e um padrão de qualidade, voltado a verdades incontestáveis (DELEUZE, 2006).

E como romper com padrões estipulados numa pesquisa acadêmica, trazendo a amorosidade nas relações com o outro nos processos de investigação? Nesse aspecto, o diálogo transforma-se também em testemunho de atos, especialmente quando a amorosidade implica dor, carências, tensões, dúvidas, bem como alegrias e prazer.

Para conhecer o sentido da amorosidade nas relações de pesquisa, é preciso analisar sintomas e processos de interações a fim de que as experiências possam ser desencadeadas em descontinuidade e permanente construção e desconstrução de sentidos. Envolve incorporar, nutrir e potencializar afetos, o que suscita entender a pesquisa também como formação de caráter, como ética, estética e política de intersubjetividade em harmonia com a mente e o sensível (DELEUZE; GUATTARI, 1995). Nesse viés, a amorosidade impulsiona-nos a pensar em partilhas sensíveis, enredos, parcerias e autoconhecimento.

Nas pesquisas (entre)laçadas que continuamos a realizar em nosso núcleo, buscamos alimentar nossas ações e interações com o outro trazendo a ética, a estética e a política sempre em evidência. Não poderia ser diferente, quando 


\section{Atos de Pesquisa em Educação - ISSN 1809-0354 \\ Blumenau, v.14, n.1, p.7-28 jan./abr. 2019 \\ DOI: http://dx.doi.org/10.7867/1809-0354.2019v14n1p7-28}

estamos realmente abertos ao desconhecido e quando colocamos de lado nossas verdades absolutas. Ao nos despirmos de ideias preconcebidas é possível conhecer a essência do outro e de nós mesmos. Segundo Conche (1998), cada pessoa busca conhecer-se melhor expondo-se em suas narrativas ao outro e, por conseguinte, refletindo-se nele. Nessa relação, o afeto pode potencializar a verdade do seu ser. Assim, a amorosidade é para os outros, fonte de interesse inesgotável; é um universo desdobrando-se na vida relacional.

O agir do pesquisador pode ser um desencadear de emoções, o que por vezes causa estranhamento e até mesmo certa resistência de outros pesquisadores, considerando as relações de amorosidade na pesquisa algo perigoso e até mesmo piegas.

No entanto, a afetividade não se encontra excluída da cognoscibilidade. As relações amorosas não se apoderam das pessoas, uma vez que não se reduzem a um sentimento afetivo, não se encontram no interior de um sujeito, não se alojam no individual, mas antes na pluralidade. Um olhar sensível que sente o mundo e as pessoas que nele vivem, vivencia o cuidado com o outro, o amor e a afetividade.

Quando o pesquisador se encontra com seus interlocutores, algo acontece. Um tempo se abre para ambos, fazendo-os viver acontecimentos que não poderiam ser vividos sem a presença de um na vida do outro. Uma pesquisa que se dá em uma relação imprevista, mas carregada de potências (DELEUZE; PARNET, 2004).

A pesquisa, então, pode ser uma experiência que não se separa da vida, uma invenção que se produz em movimento da sua própria existência. Uma escuta para as singularidades de seus interlocutores, escuta sensível que potencializa conhecimentos e saberes, libertando-nos das amarras da ciência positivista. Uma pesquisa que ultrapassa o domínio das habilidades, incitando o pensamento voltado para a vida, assumindo uma posição ética, estética e política de ser. A amorosidade, nesse aspecto, é uma prática de liberdade.

O lugar da amorosidade é um vasto mundo de paixões e ações, lugar que demanda do pesquisador e seus interlocutores um modo de ser/pensar ético, estético, político e pedagógico, apurando um sentido de coletividade. Ambos, pesquisador e interlocutores, não estão isentos de riscos nas relações 


\section{Atos de Pesquisa em Educação - ISSN 1809-0354 \\ Blumenau, v.14, n.1, p.7-28 jan./abr. 2019 \\ DOI: http://dx.doi.org/10.7867/1809-0354.2019v14n1p7-28}

comunicacionais, pois a amorosidade é um universo que se dobra e se desdobra na vida. Em tal relação, que implica estarmos aberto ao mundo, às pessoas e a tudo que ainda não conhecemos, expomos nossas crenças e nos inclinamos a querer saber como elas interferem em nossos sentidos e percepções.

A amorosidade, portanto, pode gerar incompletude e efemeridade, levandonos a paradoxos quando processamos contraditórios diferentes do que pensamos, imbuídos de tensões e dúvidas para nossas certezas (DELEUZE; GUATTARI, 2010).

Conhecer o sentido de amorosidade numa pesquisa demanda considerar sintomas dos quais depende para se fazer sensível, desencadeando experiências e processos de constante construção e desconstrução de sentidos. A amorosidade envolve modos de incorporar e nutrir afetos, o que nos leva a pensar a pesquisa também como ética, estética e política de intersubjetividade. Apresenta o sentido essencial da vida de cada um (pesquisador e interlocutores) e o modo como cada um contracena com a vida pública. Ou seja, como cada um lida com os processos de cidadania. A consciência de si e do outro nos ajuda a constituir uma filosofia de vida, pois a análise do que fazemos/pensamos nos impulsiona a buscar subsídios de compreensão na estética, na ética e na política (MEIRA, 2014).

A amorosidade nos caminhos de uma pesquisa faz-nos pensar em partilhas sensíveis, parcerias, enredos e narrativas. Suscita o desejo de variação de formas e modos de apreensão para impulsionar aproximações, contornar desvios e obstáculos que se interpõem entre o pesquisador e seus interlocutores.

E quais são esses desvios? No entendimento de Deleuze e Guattari (2010), desviar-se do padrão, do usual gera certo incômodo e desamparo, o que faz com que a relação com os interlocutores seja um misto de prazer e dor. Essa relação se constitui em experiências conflitivas, incompletas, intercaladas de dúvidas, erros e acertos. Essa diversidade de sentimentos enriquece a interação de si mesmo com o outro (DELEUZE; GUATTARI, 2010).

A amorosidade pode ser (re)significada como rede de conexões, impedindo o distanciamento do pensamento com as intersubjetividades, incluindo nesses processos a política, a ética e a estética como potências do ser. Nesse sentido, cabe 


\section{Atos de Pesquisa em Educação - ISSN 1809-0354 \\ Blumenau, v.14, n.1, p.7-28 jan./abr. 2019 \\ DOI: http://dx.doi.org/10.7867/1809-0354.2019v14n1p7-28}

a cada coletivo humano envolvido numa pesquisa inventar e (re)inventar suas próprias regras de conduta afetiva.

Ortega (2000), ao tratar da amorosidade, aposta numa certa impessoalidade, afirmando que esta proporciona sair de si e ir ao lado de fora, olhar/perceber e acolher as diferenças, o estranho e o efêmero; desamarrar-se de caminhos únicos e verdadeiros. Para o autor, podemos recriar e inventar novas maneiras de sociabilidade, como: a gentileza, a generosidade, o respeito, a solidariedade.

A tendência que está surgindo é consciente de que o convívio amoroso numa pesquisa pode ser entendido como algo em que o dentro e o fora do corpo possam harmonizar-se, compartilhando ideias em que novas metáforas possam contribuir para um novo pensar e relacionar-se. A vida que se conhece numa pesquisa é uma experiência que habita outra temporalidade, que nos convida a criar e nos movimenta para várias direções (MEIRA, 2014).

O convívio amoroso numa pesquisa se constitui no compartilhamento de ideias e sentidos em que novas metáforas vão surgindo acompanhadas de um novo pensar conectado aos movimentos da vida. Portanto, numa pesquisa, a experiência habita outra temporalidade, que nos convida a criar e buscar novos caminhos em várias direções (MEIRA, 2014).

A contradição básica que a amorosidade insere no processo de pesquisar reside no fato de que torna a pesquisa mutante, aberta a errâncias. As abstrações mentais aguçam tais movimentos e tornam a experiência sensível uma verdade sui generis, embriagada de encantamento. Complexo, misterioso, excitante, o mundo toma forma não como mera descarga de imagens, sons e corpos, mas em estado de embriaguez simbólica e energia criadora, que interfere na qualidade das relações de pesquisadores e seus interlocutores. Assim, a natureza humana é estética porque no fundo tudo é criação, com sua vertigem de morte e vida, metamorfose, destruição e construção (MEIRA, 2003).

A latência amorosa nos processos de pesquisar, especialmente em pesquisas (entre)laçadas, pode trazer outra perspectiva na ação investigativa em que estão em jogo as relações entre pesquisadores e seus interlocutores. Ambos estão sujeitos a 
mudar conceitos já preestabelecidos e especialmente sua forma de pensar sobre todas as coisas, sobre a vida.

\section{CONSIDERAÇÕES}

As reflexões provocadas neste artigo sobre a necessidade de se legitimar outros modos de pesquisar na academia deram visibilidade para a experiência e a amorosidade como elementos fundamentais para novos caminhos na academia.

Ao colocarmos em pauta a pesquisa, reiteramos os efeitos que dela provêm quando traz à luz a experiência e a amorosidade ocupando lugar de destaque nos processos de investigação e da produção de conhecimento.

A nosso ver, a experiência e a amorosidade estão na dimensão da criação e no modo de ser, que podem se modificar no próprio fazer do pesquisador e seus interlocutores. Isso significa que não se restringem ao processo de investigar, mas sobretudo à prática da própria pesquisa.

Nesse processo, os sentidos da amorosidade nas relações de pesquisa envolvem afetos que potencializam a formação de caráter do pesquisador, como a ética, a estética e a política de intersubjetividade. A amorosidade, portanto, ativa partilhas sensíveis e de autoconhecimento no percurso da pesquisa.

Isso não significa que desconsideramos a importância de outros processos de pesquisas vigentes, mas estes não devem sobrepor-se nem mesmo substituir a pesquisa que acontece na experiência, nas relações afetivas e na amorosidade.

As pesquisas realizadas em nosso núcleo e apresentadas neste artigo mostram que a experiência e a amorosidade podem abrir caminhos para outros modos de fazer/pensar pesquisa. Modos que valorizam o humano, tecendo conhecimentos e metodologias, que se desdobram em múltiplos olhares e em subjetividades.

\section{SILVIA SELL DUARTE PILLOTO}

Pós-Doutora pelo Instituto Estudos da Criança - IEC da Universidade do MINHO (UM), Portugal. Doutora em Engenharia de Produção (Gestão da Qualidade) pela Universidade Federal de Santa Catarina (UFSC). Professora titular nos cursos de 


\section{Atos de Pesquisa em Educação - ISSN 1809-0354}

Blumenau, v.14, n.1, p.7-28 jan./abr. 2019

DOI: http://dx.doi.org/10.7867/1809-0354.2019v14n1p7-28

Artes Visuais e Pedagogia e nos Programas de Pós-Graduação - Mestrado em Educação e Patrimônio Cultural e Sociedade da Universidade da Região de Joinville (UNIVILLE)

\section{CARLA CLAUBER DA SILVA}

Doutora em Educação pela Universidade Estadual de Campinas (UNICAMP). Professora da Prefeitura Municipal de Joinville.

\section{REFERÊNCIAS}

AGAMBEN, G. Infância e história: destruição da experiência e origem da história. Tradução de Henrique Búrigo. Belo Horizonte: Editora UFMG, 2005.

Autêntica, 2012.

O homem sem conteúdo. Tradução de Cláudio Oliveira. Belo Horizonte:

BARROCAS, L. C. Sentidos e significados atribuídos pelos idosos às práticas educativas vivenciadas no Centro de Referência de Assistência Social - CRAS. 2017. Dissertação (mestrado) - Universidade da Região de Joinville, Joinville.

CARGNIN, K. A. Vivências perceptivas com a infância nos espaços da escola e do museu - uma experiência. 2017. Dissertação (mestrado) - Universidade da Região de Joinville, Joinville.

CONCHE, M. A análise do amor. São Paulo: Martins Fontes, 1998.

DELEUZE, G. A literatura e a vida. In: . Crítica e clínica. Tradução de Peter

Pál Pelbart. São Paulo: 34, 2006.

(Coleção TRANS).

Bergsonismo. Tradução de Luiz B. L. Orlandi. São Paulo: 34, 1999.

; GUATTARI, F. Mil platôs - capitalismo e esquizofrenia. Tradução de Aurélio Guerra Neto e Célia Pinto Costa. Rio de Janeiro: 34, 1995. v. 1.

Muñoz. 3. ed. São Paulo: 34, 2010.

O que é a filosofia? Tradução de Bento Prado Jr. e Alberto A.

; PARNET, C. Diálogos. Tradução de José Gabriel Cunha. Lisboa: Relógio

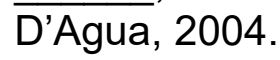

KASTRUP, V. Novas tecnologias cognitivas: o obstáculo e a invenção. In: PELLANDA, N. M. C.; PELLANDA, E. C. (orgs.). Ciberespaço: um hipertexto com Pierre Lévy. Porto Alegre: Artes e Ofícios, 2000. 


\section{Atos de Pesquisa em Educação - ISSN 1809-0354 \\ Blumenau, v.14, n.1, p.7-28 jan./abr. 2019 \\ DOI: http://dx.doi.org/10.7867/1809-0354.2019v14n1p7-28}

LARROSA, J. Tremores: escritos sobre experiência. Tradução de Cristina Antuns e João Wanderley Geraldi. Belo Horizonte: Autêntica, 2014. (Coleção Educação, experiência e sentido).

MEIRA, M. Filosofia da criação: reflexões sobre o sentido do sensível. Porto Alegre: Mediação, 2003.

O sentido de aprender pelos sentidos. In: PILLOTTO, S. S. D; BOHN, L. R. D. Arte/educação: ensinar e aprender no ensino básico. Joinville: Editora UNIVILLE, 2014.

NATUME, H. Musicalização: memórias, experiências e sensibilidades na terceira idade. 2018. Dissertação (mestrado) - Universidade da Região de Joinville, Joinville.

OPIPARI, C.; TIMBERT, S. Transversalidades - cartografia imaginada na mangueira. In: PASSOS, E.; KASTRUP, V.; TEDESCO, S. (orgs.). Pistas do método da cartografia: a experiência da pesquisa e o plano comum. Porto Alegre: Sulina, 2014.

ORTEGA, F. Para uma política da amizade: Arendt, Derrida, Foucault. Rio de Janeiro: Relume Dumará, 2000.

PASSOS, E.; KASTRUP, V.; ESCÓSSIA, L. da (orgs.). Pistas do método da cartografia: pesquisa-intervenção e produção de subjetividade. Porto Alegre: Sulina, 2015.

PASSOS, E.; KASTRUP, V.; TEDESCO, S. (orgs.). Pistas do método da cartografia: a experiência da pesquisa e o plano comum. Porto Alegre: Sulina, 2014.

PIRES, J. C. de A. Sentidos e experiências na docência: processos de aprendizagem do instrumento musical na infância. 2017. Dissertação (mestrado) Universidade da Região de Joinville, Joinville.

SCHREIBER, A. C. Q. Memórias e sentidos na terceira idade: experiência pela vida da estética. 2018. Dissertação (mestrado) - Universidade da Região de Joinville, Joinville.

STRAPAZZON, M. A. L. Uma cartografia com a infância: experiências e múltiplas sonoridades. 2017. Dissertação (mestrado) - Universidade da Região de Joinville, Joinville.

VIANA, D. C.. Mediação cultural por meio da dança/educação como possibilidade de aprendizagem na infância. 2016. Dissertação (mestrado) - Universidade da Região de Joinville, Joinville. 